\title{
Effect of Personality on the Number of Feedback Requests When Learning a Golf-Putting Task
}

\author{
Tadao Ishikura \\ Faculty of Sports Science and Health, Doshisha University, Kyoto, Japan \\ Email:tishikur@mail.doshisha.ac.jp
}

How to cite this paper: Ishikura, T. (2016). Effect of Personality on the Number of Feedback Requests When Learning a GolfPutting Task. Advances in Physical Education, 6, 389-395.

http://dx.doi.org/10.4236/ape.2016.64039

Received: October 6, 2016

Accepted: November 3, 2016

Published: November 7, 2016

Copyright $\odot 2016$ by author and Scientific Research Publishing Inc. This work is licensed under the Creative Commons Attribution International License (CC BY 4.0).

http://creativecommons.org/licenses/by/4.0/

\begin{abstract}
This study examined how personality influences the number of feedback requests and anxiety when learning to putt in golf. Twenty university students (10 males and 10 female) stood in front of a partition and putted a golf ball, with the goal of having the ball stop on a line $3.5 \mathrm{~m}$ from the starting position, along a path that included uphill and downhill portions. I used the Japanese version of the Big Five Personality Inventory (Big Five) to evaluate participants' personalities and the Japanese version of the State-Trait Anxiety Inventory Form (STAI-JYZ) to evaluate participants' anxiety. After a pretest, participants completed 60 practice trials in which they were allowed to ask how far the ball went if and when they wanted to. All participants then performed a posttest. Results showed that constant error, variable error, and total variability were lower at posttest than pretest. In addition, the results of a multiple regression analysis showed that higher Big Five agreeableness scale and STAI-JYZ anxiety-present scale scores were associated with fewer requests for feedback. These results suggest that the number of feedback requests was related to consideration and awareness, and these findings have implications for future research on cooperation.
\end{abstract}

\section{Keywords}

Feedback, Personality, Anxiety, Self-Controlled Practice

\section{Introduction}

When acquiring motor skills, learners receive information about action errors and correct subsequent actions. Consequently, learners become able to perform the action reliably and accurately. After performing the action, the resulting external feedback provides information about error detection and correction for future performance. Therefore, feedback is important for acquiring motor skills (Schmidt, 1991; Wulf, Shea, \& Lewthwaite, 2010). 
Self-controlled practice in which a learner can freely request feedback information is more conducive to learning than practice with a predetermined feedback schedule (Wulf et al., 2010). Patterson and Carter (2010) indicated that retention and transfer were superior when learners controlled the knowledge of results schedule during acquisition of a novel sequential timing task. These results are similar to Chiviacowsky and Wulf (2002), who found that requested knowledge of results increased when participants performed well. The number of feedback requests depends on task characteristics, reflects the learner's independence, motivation, and previous experience, and may be more important than the amount of feedback the learner actually receives (Chiviacowsky \& Wulf, 2002).

Personality and anxiety may affect attitude toward learning or practice strategy (e.g., the number of feedback requests). For example, Zhang (2003) examined the relationship between university students' learning approaches and Big Five personality traits. The results showed that Conscientiousness, Openness, Neuroticism, and Agreeableness were good predictors of learning approaches. However, Extraversion was not related to any of the learning approaches. The personality trait of Intellect is independent from grade point average (GPA) in undergraduate students, and effort regulation mediates the relationship between Conscientiousness and Agreeableness (Bidjerano \& Yun Dai, 2007). Chamorro-Premuzic and Furnham (2008) reported that in undergraduate students, the highest correlation occurred between Conscientiousness and academic performance, which was operationalized in terms of second-year exam results, and a positive correlation was present between Openness to experience and academic performance. In contrast, because there is a negative relationship between anxiety and performance on cognitive tasks (Eysenck \& Calvo, 1992; Eysenck, Derakshan, Santos, \& Calvo, 2007), it has been predicted that anxiety would affect cognitive strategy during motor learning. However, there are conflicting views on how anxiety affects motor performance and motor learning (Masters, 1992; Neiva, Massa, Barros, \& Meira, 2014). Based on these reports, it has been hypothesized that requests for feedback are related to personality characteristics and anxiety. For example, Bokums, Meira, Neiva, Oliva, and Maia (2012) examined the relationship between trait anxiety and self-controlled frequency of feedback during acquisition of the overhand volleyball serve. The results showed that although there was not an interaction between acquisition and transfer-test performance, the high anxiety participants requested more feedback than the low anxiety participants.

This study examined the relationships between the number of feedback requests, personality, and anxiety while learning a golf-putting task. I hypothesized that there would be relationships between Conscientiousness, Agreeableness, and Openness to experience and the number of feedback requests, and that participants with higher anxiety would request more feedback than those with lower anxiety.

\section{Method}

This experiment was conducted after obtaining approval from the Doshisha University 
Ethics Committee for Scientific Research Involving Human Subjects.

\section{Participants}

Twenty healthy university students ( 10 male and 10 female; $M=20.6$ years, $S D=1.3$ years) participated in this experiment. Participants had no prior experience learning golf putting, and all were right-hand dominant or preferred. Participants gave written informed consent and received/1000 cash as remuneration for participation.

Task, Materials, and Design

First, participants completed the Japanese version of the Big Five Personality Inventory (Big Five; Gakugei-Tosyo, Inc., Tokyo, Japan) which consist of 70 items to measure personality traits, and the Japanese version of the State-Trait Anxiety Inventory Form (STAI-JYZ; Jitsumukyoiku-shuppan, Inc., Tokyo, Japan) which consist of 40 items to measure anxiety. The Big Five includes five subscales based on the Big Five hypothesis (Goldberg, 1981), which assumes that there are five basic personality traits: Extraversion, Agreeableness, Conscientiousness, Neuroticism, and Openness to experience. Extraversion reflects psychological energy turned to others or objects. Agreeableness reflects the degree of cooperativeness with others. Conscientiousness is related to self-control and the reliability and effectiveness of planning. Neuroticism refers to anaphylaxis of emotion, and a tendency to become confused in response to a stressor. Openness to experience reflects the degree of curiosity and concern about inner or external worlds. Most of an individual's personality can be described by interpreting the combined Big Five score. The STAI-JYZ consists of Japanese items translated from the STAI (Spielberger \& Sydeman, 1994), and includes four subscales: state-anxiety: anxiety-present, state-anxiety: anxiety-absent, trait-anxiety: anxiety-present, and traitanxiety: anxiety-absent. State-anxiety reflects transient reactions to a phenomenon that evokes anxiety, and changes over time. Trait-anxiety is anxiety that is relatively stable across various situations. Anxiety-present is when anxiety exists (e.g., feeling diffident), and anxiety-absent is when anxiety does not exist (e.g., feeling fortunate). The reliability and suitability of the Japanese version of the Big Five Personality Inventory and the Japanese version of the State-Trait Anxiety Inventory Form are checked and reported (Murakami \& Murakami, 1997; Hidano, Fukuhara, Iwasaki, Soga, \& Spielberger, 2000).

Participants stood behind a partition and putted a golf ball with the goal of having the ball stop on a line $3.5 \mathrm{~m}$ from the starting position. To add difficulty, the path included uphill and downhill portions (see Figure 1).

Participants completed 60 putting trials. They were allowed to ask how far the ball rolled at the end of a trial. The pre- and post-test included three trials each, without feedback. After the trials, participants reported their level of confidence in their ability to stop the ball between 3.375 and $3.625 \mathrm{~m}$ (within $10 \%$ of $3.5 \mathrm{~m}$ ) on a scale from $0 \%$ $100 \%$.

\section{Dependent Variables}

The number of feedback requests during the 60 practice trials was grouped in blocks of 10 trials. Dependent variables for pre- and post-test performance were constant error (CE), variable error (VE), and the total variability (TV). The level of confidence reported in pre- and post-tests was used to assess the cognitive aspect of skill acquisition. 


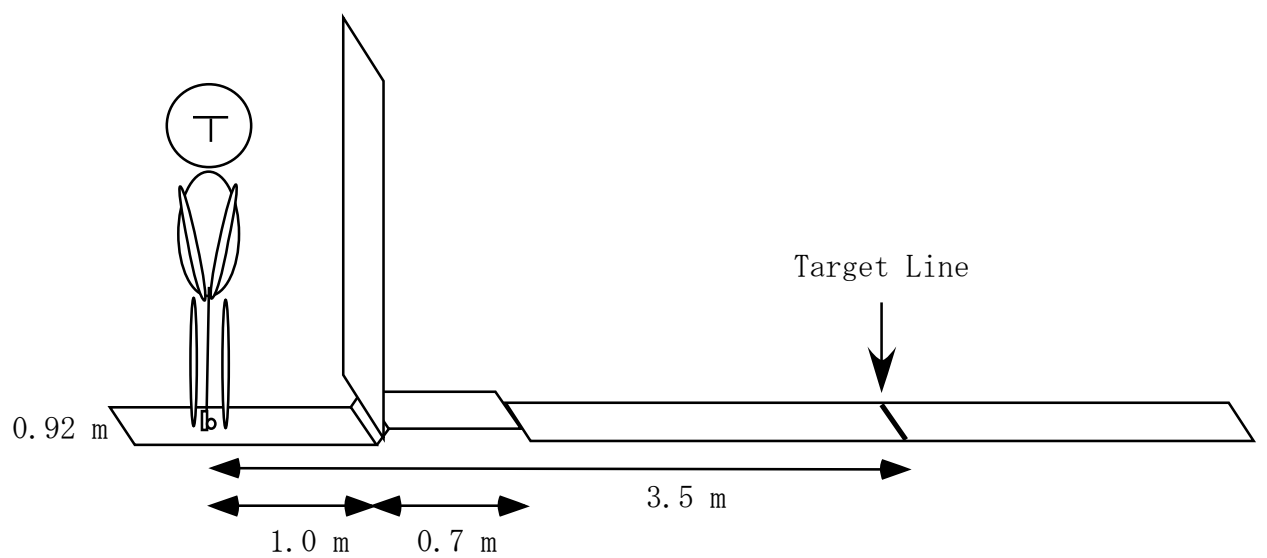

Figure 1. Experimental conditions.

Relationships between the number of feedback requests during practice, personality, and anxiety were evaluated using Big Five subscale scores (extraversion, agreeableness, conscientiousness, neuroticism, and openness to experience) and STAI-JYZ subscale scores (state-anxiety: anxiety-present scale, state-anxiety: anxiety-absent scale, traitanxiety: anxiety-present scale, and trait-anxiety: anxiety-absent scale).

\section{Results}

IBM SPSS Statistics Version 22 (IBM SPSS Japan, Inc., Tokyo, Japan) was used for all statistical analyses. The level of significance was set at $p<.05$. Because there were no significant differences between male and female participants for any dependent variable, we did not include sex as a factor in the analyses.

\section{Number of Feedback Requests}

A one-way repeated-measures analysis of variance (ANOVA) was used to assess differences in the number of feedback requests between pre- and post-test. The mean number of requests for feedback was 35.1 (range $=8$ - 59), and there was no significant difference between the first (6.20) and last (6.45) ten trials.

\section{Acquisition}

One-way repeated-measures analysis of variance (ANOVA) on CE, VE, and TV were used to evaluate acquisition. There were significant differences in CE ( $F_{1.19}=16.30$, $p<.001)$, VE $\left(F_{1.19}=9.90, p<.005\right)$, and TV $\left(F_{1.19}=47.87, p<.001\right)$. Post-test values were lower than pre-test values (see Table 1).

\section{Number of Feedback Requests and Acquisition}

Table 1. Pre- and post-test performance.

\begin{tabular}{|c|c|c|c|c|c|c|c|c|c|}
\hline \multirow{2}{*}{ Test } & \multicolumn{2}{|c|}{$\mathrm{CE}$} & & \multicolumn{2}{|c|}{$\mathrm{VE}$} & \multicolumn{4}{|c|}{$\mathrm{TV}$} \\
\hline & $\underline{\mathrm{M}}$ & $\underline{\mathrm{SD}}$ & & $\underline{\mathrm{M}}$ & $\underline{\mathrm{SD}}$ & & $\underline{\mathrm{M}}$ & $\underline{\mathrm{SD}}$ & \\
\hline Pre & 90.00 & 86.00 & $p<.001$ & 71.74 & 46.86 & $p<.05$ & 138.24 & 58.41 & $p<.001$ \\
\hline Post & 19.50 & 40.90 & & 38.20 & 16.21 & & 53.30 & 29.68 & \\
\hline
\end{tabular}

M: Mean. SD: Standard Deviation. CE: Constant Error. VE: Variable Error. TV: Total Variability. 
A two-tailed Pearson correlation was used to assess the relationship between the number of feedback requests and skill acquisition. There was no significant relationship.

\section{Confidence}

A one-way repeated-measures analysis of variance (ANOVA) was used to assess differences in confidence between pre- and post-test. Confidence did not differ between pre-test $(28.05 \% \pm 13.16 \%)$ and post-test $(34.20 \% \pm 19.82 \%)$.

\section{Personality and the Number of Feedback Requests}

A stepwise multiple regression analysis was conducted to evaluate the relationship between personality and number of feedback requests. The dependent variable was the number of feedback requests, and the independent variables were Big Five and STAI-JYZ scores. The regression was significant $\left(r=.68, F_{2.19}=7.44, p<.005\right)$. Fewer feedback requests were associated with higher scores on the Big Five Agreeableness scale (standardized partial regression coefficient $=-.681$ ) and the STAI-JYZ Trait-anxiety: Anxiety-present scale (standardized partial regression coefficient $=-.466$; see Figure 2).

\section{Relationship between Personality and Performance}

A stepwise multiple-regression analysis was conducted to evaluate the relationship between personality and performance. The dependent variables were the CE, VE, and TV at pre- and post-test, and the independent variables were Big Five and STAI-JYZ scores. The regression was not significant.

\section{Discussion}

The purpose of this study was to examine the relationship among the number of feedback

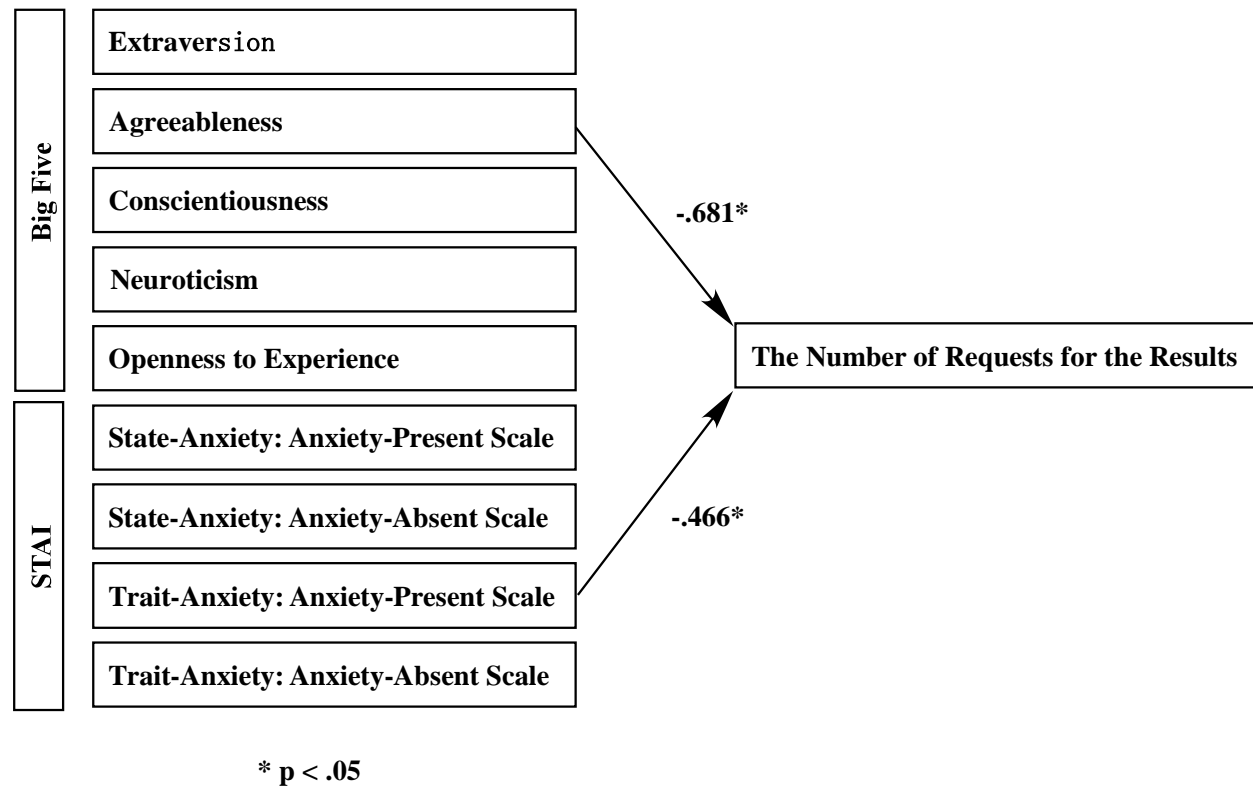

Figure 2. Results of multiple regression analysis. Note: The numerical values in the figure are standardized partial regression coefficients. 
requests in a golf-putting task, personality, and anxiety. I predicted that Conscientiousness, Agreeableness, and Openness to experience of the Big Five scale, and higher anxiety would be associated with more requests for feedback. The results showed that although participants improved at the golf-putting task and the number of feedback requests was associated with agreeableness and trait anxiety (anxiety-present), there was no relationship between performance and personality or anxiety. These results do not support the hypothesis, and individuals with a highly agreeable personality and high trait anxiety did not request a great deal of feedback. This is in contrast to Bokums et al. (2012), who reported that participants with higher trait anxiety requested far more feedback than those with lower trait anxiety.

Compared with individuals from other nations, Japanese individuals show high agreeableness on the Big Five (McCrae, Yik, Trapness, Bond, \& Paulhus, 1998). Accordingly, it may be that in the current study anxious participants wanted to avoid bothering others and to finish the experiment without interruption, which was achieved by not asking the experimenter for feedback. That is, participants who were highly anxious and agreeable did not feel anxiety with respect to learning the task; instead, they were concerned for the experimenter and felt constrained in asking for feedback. A highly anxious and agreeable individual might consider it more important to foster a relationship with the experimenter, rather than acquire the skill. Thus, cross-cultural personality factors might affect the number of feedback requests. It may be necessary to set up Japanese group and other country's group, and to re-examine effects of crosscultural factor.

\section{References}

Bidjerano, T., \& Yun Dai, D. (2007). The Relationship between the Big-Five Model of Personality and Self-Regulated Learning Strategies. Learning and Individual Differences, 17, 69-81. http://dx.doi.org/10.1016/j.lindif.2007.02.001

Bokums, R. M., Meira, C. M., Jr., Neiva, J. F. O, Olivia, T., \& Maia, J. F. (2012). Self-Controlled Feedback and Trait Anxiety in Motor Skill Scquisition. Psychology, 3, 406-409. http://dx.doi.org/10.4236/psych.2012.35057

Chamorro-Premuzic, T., \& Furnham, A. (2008). Personality, Intelligence and Approaches to Learning as Predictors of Academic Performance. Personality and Individual Differences, 44, 1596-1603. http://dx.doi.org/10.1016/j.paid.2008.01.003

Chiviacowsky, S., \& Wulf, G. (2002). Self-Controlled Feedback: Does It Enhance Learning Because Performers Get Feedback When They Need It? Research Quarterly for Exercise and Sports, 73, 408-415. http://dx.doi.org/10.1080/02701367.2002.10609040

Eysenck, M. W., \& Calvo, M. G. (1992). Anxiety and Performance: The Processing Efficiency Theory. Cognition and Emotion, 6, 409-434. http://dx.doi.org/10.1080/02699939208409696

Eysenck, M. W., Derakshan, N., Santos, R., \& Calvo M. G. (2007). Anxiety and Cognitive Performance: Attentional Control Theory. Emotion, 7, 336-353.

http://dx.doi.org/10.1037/1528-3542.7.2.336

Goldberg, L. (1981). Language and Individual Differences: The Search for Universals in Personality Lexicons. In L. Wheeler (Ed.), Review of Personality and Social Psychology (pp. 141-165). Beverly Hills, CA: Sage Publication. 
Hidano, T., Fukuhara, M., Iwasaki, S., Soga, S., \& Spielberger, C. D. (2000) A New Edition STAI Manual. Tokyo: Jitumukyoiku-shuppan. (In Japanese)

Masters, R. S. W. (1992). Knowledge, Knerves, and Know-How: The Role of Explicit versus Implicit Knowledge in the Breakdown of a Complex Motor Skill under Pressure. British Journal of Psychology, 83, 343-358. http://dx.doi.org/10.1111/j.2044-8295.1992.tb02446.x

McCrae, R. R., Yik, M. S. M., Trapnell, P. D., Bond, M. H., \& Paulhus, D. L. (1998). Interpersonality Profiles across Cultures: Bilingual, Acculturation, and Peer Rating Studies of Chinese Undergraduates. Journal of Personality and Social Psychology, 74, 1041-1055. http://dx.doi.org/10.1037/0022-3514.74.4.1041

Murakami, Y., \& Murakami, C. (1997) Scale Construction of a "Big Five" Personality Inventory. The Japanese Journal of Personality, 6, 29-39. (In Japanese)

Neiva, J. F. O, Massa, M., Barros, J. A. C, \& Meira, C. M. Jr. (2014). Trait Anxiety and Goal Difficulty on Learning to Climb the Bachman Ladder. Perceptual and Motor Skills, 118, 375-383. http://dx.doi.org/10.2466/22.25.PMS.118k17w0

Patterson, J. T., \& Carter, M. (2010). Learner Regulated Knowledge of Results during the Acquisition of Multiple Timing Goals. Human Movement Science, 29, 214-227. http://dx.doi.org/10.1016/j.humov.2009.12.003

Schmidt, R. A. (1991). Motor Learning and Performance: From Principles to Practice. Champaign, IL: Human Kinetics.

Spielberger, C. D., \& Sydeman, S. J. (1994). State-Trait Anxiety Inventory and State-Trait Anger Expression Inventory. In M. E. Maruish (Ed.), The Use of Psychological Testing for Treatment Planning and Outcome Assessment (pp. 292-332). Hillsdale, NJ: Lawrence Erlbaum Associates.

Wulf, G., Shea, C., \& Lewthwaite, R. (2010). Motor Skill Learning and Performance: A Review of Influential Factors. Medical Education, 44, 75-84.

http://dx.doi.org/10.1111/j.1365-2923.2009.03421.x

Zhang, L. (2003). Does the Big Five Predict Learning Approaches? Personality and Individual Differences, 34, 1431-1446. http://dx.doi.org/10.1016/S0191-8869(02)00125-3

Submit or recommend next manuscript to SCIRP and we will provide best service for you:

Accepting pre-submission inquiries through Email, Facebook, LinkedIn, Twitter, etc.

A wide selection of journals (inclusive of 9 subjects, more than 200 journals)

Providing 24-hour high-quality service

User-friendly online submission system

Fair and swift peer-review system

Efficient typesetting and proofreading procedure

Display of the result of downloads and visits, as well as the number of cited articles

Maximum dissemination of your research work

Submit your manuscript at: http://papersubmission.scirp.org/

Or contact ape@scirp.org 